\title{
AN EXPLORATION OF STUDENT ATTITUDES ON PRIVACY/SECURITY ISSUES: FACEBOOK USAGE CONCERNS AND EXPECTATIONS
}

\author{
Sushma Mishra, Robert Morris University, mishra@rmu.edu \\ Peter J. Draus, Robert Morris University, draus@rmu.edu \\ Gregory J. Leone, Robert Morris University, leone@rmu.edu \\ Donald J. Caputo, Robert Morris University, caputo@rmu.edu
}

\begin{abstract}
The technological advent of Social Media, powered and enhanced in great measure by the introduction of Facebook, has generated the need for an exploratory and in-depth research study of the privacy and security implications inherent in Social Networking Sites (SNS), and the responses of the students that engage in this sphere of activity interaction through Facebook integration. In this study, we examine and categorize the privacy and security concerns of undergraduate college students at the time of entry into the SNS environment and in the period beyond the entry stage. A survey instrument of twenty-four relevant privacy and security questions and accompanying demographic data was designed, disseminated to the undergraduate students, and analyzed. The three research questions revolved around these factors: the privacy concerns of undergraduate students when first encountering the Facebook environment, differences in perception due to the gender of the user in regard to privacy concerns about Facebook, and changes in privacy concerns with continued usage over a period of time. The primary concerns analyzed within and between groups are: personal privacy, identity theft, stalking, harassment/flaming, and future employment consequences. We conclude with a discussion of results and recommendations for future research trajectories.
\end{abstract}

Keywords: Facebook, privacy, flaming, ANOVA, students, SPSS, Gender differences, survey

\section{INTRODUCTION}

The inauguration of Social Media, with Facebook as the foremost innovative social networking force, has occurred rapidly over a short time period, with a corresponding rise of potential areas of risk and controversy. The dramatic increase in popularity of Social Networking Sites (SNS) over the years in young adults has raised pertinent questions in terms of privacy issues arising from the emergence of the extensive subset of user data on such platforms. A large population of Facebook users resides between the ages of 18 and 25, which is a higher membership for the reported age group than any other SNS [8]. Facebook is believed to have outgrown all other SNS with an estimated 157\% growth from 2008 to 2009. It is positioned to be the fourth largest Internet site in the world, after Google, Microsoft and Yahoo. There have been several criticisms about lack of functionality on Facebook that would lead to more privacy for users [11]. Research in the area of Facebook privacy identifies several areas of concern for users: public accessibility to information leading to identity theft [11], sharing of personal information by third parties without user consent [10], and friends or peers sharing information of a user [11].

Jung et al (2011) claim that privacy has been a critical issue in SNS use because people need to disclose their personal information and share them with others who are connected with them, or even those who are not connected, in order to join and use SNS. Privacy concerns have consistently been cited as the main reason for non-internet users to decline using the Internet (Westin 2003). Dinev and Hart (2006) argue that individuals will disclose information if they perceive that the overall benefit of such disclosure is balanced by the assessed risk of sharing information. College students as a community are avid users of sites such as Facebook. There are several studies that have used Facebook to study the behavior of students on SNS and the ways it impacts their lives in general.

This is an exploratory study where we want to understand the privacy concerns of undergraduate students upon joining a SNS. The research questions guiding this study are: the privacy concerns of undergraduate students

RQ1: What are some of the privacy concerns of undergraduate students upon joining a SNS such as Facebook? 


\section{Issues in Information Systems}

Volume 13, Issue 1, pp. 340-349, 2012

RQ2: Is there a difference in perception due to the gender of the user about the privacy concerns on Facebook?

RQ3: Do privacy concerns of the users change, and in what manner, with continued usage of Facebook over time?

The rest of this paper is organized as follows: after the introduction of the topic, a brief literature review of the extant literature is followed. The literature review is followed by data collection and analysis section. Following the data collection and results, a discussion of the findings is presented. The contributions are listed and limitations are stated. The last section presents the conclusion of this study.

\section{LITERATURE REVIEW}

There have been several reported privacy breaches in media, and maintaining privacy on SNS is a challenge. Also, very little explanation or help is being offered by these popular SNS to help individuals plan their privacy protection [14]. It has been argued over the years that personal data stored along with usage behavior of individuals of such sites are analyzed or mined for patterns and trends and transmitted to third parties with user consent [7]. Privacy related threats could also be based on "profile information" of users employing face recognition, content-based image retrieval as well as image tagging and cross profiling leading to phishing attacks, information leakage, profile squatting, stalking, flaming and corporate espionage [3]. Frequent usage of services on SNS might eventually lead to the identification of fraud [8], online harassment [15], physical stalking (based on the availability of personal information on OSNs) [8], cyber-mobbing [13] or cyber-bullying, which surfaces as circulating false rumors about a person or posting derogatory messages on one's user site) [4],[15]. Thus there can be several causes of concerns when students today are using these websites for sharing information as this information could be used in unforeseen ways. This paper addresses some of these common threats of information misuse and articulates student perception about these possibilities of privacy threats.

This study also looks at the perception of security and privacy issues related to extensive SNS usage. Even though Facebook has one of the most widely used SNS today with more that 500 million users, there have been several instances of criticisms regarding privacy violation on this platform [11]. There are various risks that are associated with public accessibility of user's information. Some of these are: sharing and collecting information by an unauthorized third party, identity theft and information use of security attacks such as social engineering or phishing [10]. It would be correct to assume that the investigation of users' privacy concerns and subsequent behaviors on SNS should consider the group interaction dynamics as well as interpersonal relationships on SNS.

There have been several studies to understand the complexity of privacy on SNS from various perspectives. Xu (2007) examined what kind of concerns users have regarding the privacy of their data on such websites. The study also examined the perceived level of control for users over privacy breaches of their information. Hempel and Lehman (2005) have studied online privacy management tools available to the users and appropriate behavioral cues for the same. Research in SNS privacy policies informs us about inadequacies that have led to the belief that ethics in designing such policies is of utmost importance (McGrath et al. 2008). Studies also suggest that there are issues with actual architectural design of some SNS that might lead to erosion in privacy of users [18]. Most of these studies examine the risk of making personal information accessible to the public through SNS usage. There are other risks involved in SNS usage as well. For example, misuse of the information by acquaintances on such sites. Most of these sites lack an ability to monitor peer usage behavior and hence the capability to stop any type of snooping. As Krasnova et al. (2010) implies, the uncertainty of negative outcomes might be magnified by the lack of face-toface contact and visual cues, which will in turn influence information disclosure on SNS. Researchers in the SNS area have looked at several aspects of Facebook usage including privacy issues, and motivations to start using relationship management techniques [18], [20]. There have been studies on Facebook's social features covering the benefits of social networking sites, the benefits of Facebook "Friends," and the relationship between Facebook use and maintenance of social capital [19].

There have been several studies specifically aimed at college student behavior online and their privacy issues. In a study by Gross et al. (2005), where the authors analyzed the online behavior of students at Carnegie Mellon University at a popular SNS, suggests that there are diverse potential attacks on various facets of privacy, exemplary stalking, demographics, face re-identification, social security numbers and identity theft. In order to know whether these students understand their privacy privileges on these websites, Acquisti and Gross (2006) conducted a survey. 


\section{Issues in Information Systems}

Volume 13, Issue 1, pp. 340-349, 2012

Results suggested that even though a huge number of students claimed that they understood their privacy settings on these sites, there were a considerable number of students who were unaware of such privileges.

The accuracy of information shared by undergraduate students on SNS such as Facebook is impressive. In a study by Young and Quan-Haase (2009), some interesting facts about undergraduate students' Facebook usage was presented: 99.35 percent of respondents use their actual first and last name in their profile. Nearly two-thirds present their sexual orientation and interests (favorite movies, activities and books); 83.1 percent provide their e-mail address, 92.2 percent their date of birth, 80.5 percent their current town in which they live, 97.7 percent present an image of themselves, and 96.1 percent offer photographs of friends.

Tufekci (2008), in a study on privacy issues on Facebook, suggests that demographic variables are a more important concern to undergraduate students on Facebook than future audiences. The study also suggests that more real concern of audiences like the government, companies and employer surveillance was less relevant to these students. Hence, it seems to be that these young respondents more often refer to choices regarding current concerns, (for example, as long as parents are not reading their journals) and are less concerned about future threats (Tufekci, 2008).

Krasnova et al. (2009) studied the attitude of SNS users in terms of weighing of privacy costs and benefits of using such sites. The motivation was to study the choices that these users would make when facing different trade-offs relating to privacy decisions. Their results show that a significant number of such users were "unconcerned socializers", who seem to significantly underestimate risks concerning their participation in SNS such as Facebook. They also reported that female users of this young age group seemed to be more conscious of their privacy options than males and they were more concerned about controlling the accessibility of the information that they were providing on these sites. Krasnodar et al. (2009) suggest that users tend to reduce the amount of information they disclose in accordance with their privacy concerns.

In summary, the research literature in SNS usage and privacy concerns of users suggests two things. First, young users such as high school or undergraduate students tend to provide a plethora of personal information with accuracy on these websites and do not seem to be bothered about the fact that this information might be misused by a third party. Second, female users seem to be more concerned about misuse of their personal information on such websites and tend to use more caution when reporting personal data on these platforms than their male counterparts. This study is building upon these inferences from the literature.

\section{Demographics}

\section{DATA COLLECTION AND ANALYSIS}

A survey was administered in a northeastern small private school. The survey consisting of 24 questions was administered in an introductory INFS course that is part of the university core curriculum. The sample consisted of $60 \%$ men, $40 \%$ women, which closely matched the university's overall gender distribution of $56 \%$ to $44 \%$. 126 out of the 129 subjects used Facebook as their primary social media site. The years of Facebook usage ranged from less than 1 year to up to 11 years with a mean of 3.7 years. The survey gathered basic demographic information as well as questions on their reasons for joining and continuing to participate in social media sites as well as concerns they had both before joining and after participating in social media sites. There were five questions on the survey dealing with privacy concerns in Facebook. The results of those questions will show that about $1 / 4$ of the subjects were concerned with privacy issues, with between $43 \%$ and $48 \%$ indicating much concern. Somewhat surprisingly, given the consistency of the other privacy questions, $85 \%$ reported that they were aware that content may be used by future employers.

\section{RESULTS}

An analysis of the students concerns in using Facebook, both when they started, and after they had used it for a while showed that, in the five areas that were examined, less than $25 \%$ had any concerns at all. This dropped to only $11 \%$ after they had used Facebook more frequently. The mean number of years they had been using Facebook was 3.6 for the sample. All of their concerns dropped, and in this sample (table 1), after using Facebook, generally over $90 \%$ of the users had none of these concerns. 


\section{Issues in Information Systems}

Volume 13, Issue 1, pp. 340-349, 2012

Table 1. Student concerns on Facebook privacy

\begin{tabular}{|l|l|l|l|l|l|}
\hline \multicolumn{2}{c}{ Joining } & \multicolumn{5}{l|}{ Continuing } \\
\hline Concerns & $\mathrm{N}$ & $\%$ & $\mathrm{~N}$ & $\%$ & Diff \\
\hline Personal Privacy & 30 & $24 \%$ & 10 & $8 \%$ & -20 \\
Identify theft & 24 & $19 \%$ & 8 & $6 \%$ & -16 \\
Stalking & 26 & $21 \%$ & 10 & $8 \%$ & -16 \\
Harassment/flaming & 21 & $17 \%$ & 7 & $6 \%$ & -14 \\
Future employment & 21 & $17 \%$ & 11 & $9 \%$ & -10 \\
\hline
\end{tabular}

Table 2: ANOVA for student privacy concerns

\begin{tabular}{|c|c|c|c|c|c|c|}
\hline & & Sum of Squares & $\mathrm{df}$ & Mean Square & $\mathrm{F}$ & Sig. \\
\hline privacy_both & $\begin{array}{l}\text { Between Groups } \\
\text { Within Groups } \\
\text { Total }\end{array}$ & $\begin{array}{l}1.689 \\
17.695 \\
19.385\end{array}$ & $\begin{array}{l}1 \\
76 \\
77\end{array}$ & $\begin{array}{l}1.689 \\
.233\end{array}$ & 7.256 & .009 \\
\hline stalking_both & $\begin{array}{l}\text { Between Groups } \\
\text { Within Groups } \\
\text { Total }\end{array}$ & $\begin{array}{l}1.106 \\
19.825 \\
20.930\end{array}$ & $\begin{array}{l}1 \\
84 \\
85\end{array}$ & $\begin{array}{l}1.106 \\
.236\end{array}$ & 4.684 & .033 \\
\hline flaming_both & $\begin{array}{l}\text { Between Groups } \\
\text { Within Groups } \\
\text { Total }\end{array}$ & $\begin{array}{l}889 \\
18.766 \\
19.656\end{array}$ & $\begin{array}{l}1 \\
88 \\
89\end{array}$ & $\begin{array}{l}.889 \\
.213\end{array}$ & 4.170 & .044 \\
\hline identiy_cont & $\begin{array}{l}\text { Between Groups } \\
\text { Within Groups } \\
\text { Total }\end{array}$ & $\begin{array}{l}2.685 \\
40.993 \\
43.678\end{array}$ & $\begin{array}{l}1 \\
85 \\
86\end{array}$ & $\begin{array}{l}2.685 \\
.482\end{array}$ & 5.567 & .021 \\
\hline privacy_cont & $\begin{array}{l}\text { Between Groups } \\
\text { Within Groups } \\
\text { Total }\end{array}$ & $\begin{array}{l}5.241 \\
36.977 \\
42.218\end{array}$ & $\begin{array}{l}1 \\
76 \\
77\end{array}$ & $\begin{array}{l}5.241 \\
.487\end{array}$ & 10.771 & .002 \\
\hline stalking_cont & $\begin{array}{l}\text { Between Groups } \\
\text { Within Groups } \\
\text { Total }\end{array}$ & $\begin{array}{l}3.621 \\
43.460 \\
47.081\end{array}$ & $\begin{array}{l}1 \\
84 \\
85\end{array}$ & $\begin{array}{l}3.621 \\
.517\end{array}$ & 6.999 & .010 \\
\hline flaming_cont & $\begin{array}{l}\text { Between Groups } \\
\text { Within Groups } \\
\text { Total }\end{array}$ & $\begin{array}{l}1.931 \\
38.024 \\
39.956\end{array}$ & $\begin{array}{l}1 \\
88 \\
89\end{array}$ & $\begin{array}{l}1.931 \\
432\end{array}$ & 4.470 & .037 \\
\hline
\end{tabular}




\section{Issues in Information Systems}

Volume 13, Issue 1, pp. 340-349, 2012

It is interesting to note that while only $9 \%$ reported being concerned about future employers looking at their Facebook content, $85 \%$ reported knowing that the content would be reviewed by future employers. The other interesting item from this data was that the rank of the employer tracking concern went from the second highest concern when joining, to the lowest concern now. This is even more intriguing, since they are now much closer to career employment than they would have been when they joined.

An ANOVA analysis of both the concerns when joining and their current concerns based on gender did show significant differences (table 2). So while there were few people who had concerns, those that did show concerns in certain areas were more likely to be women. Three areas were the same, both when joining and now. Those areas are: Privacy, Stalking and Flaming. There were no gender differences for identity theft when joining, but there were for those who had been using Facebook for a longer term.

The counts for the groups are shown below:

Table 3: Gender * privacy_both Cross-tabulation

Count

\begin{tabular}{|ll|l|l|l|}
\hline \multirow{4}{*}{} & \multicolumn{2}{|l|}{ privacy_both } & \multirow{2}{*}{} \\
\cline { 2 - 4 } & & 00 & 1.00 & Total \\
\hline Gender & 1 & 26 & 18 & 44 \\
& 2 & 10 & 24 & 34 \\
Total & & 36 & 42 & 78 \\
\hline
\end{tabular}

Table 4: Gender * stalking_both Cross-tabulation

\begin{tabular}{|ll|l|l|l|}
\hline \multirow{2}{*}{} & \multicolumn{2}{|l|}{ stalking_both } & \multirow{2}{*}{ Total } \\
\cline { 2 - 4 } & .00 & 1.00 & To \\
\hline Gender & 1 & 35 & 17 & 52 \\
& 2 & 15 & 19 & 34 \\
Total & & 50 & 36 & 86 \\
\hline
\end{tabular}

Table 5: Gender * flaming_both Cross-tabulation

\begin{tabular}{|ll|l|l|l|}
\hline \multirow{4}{*}{} & \multicolumn{2}{|l|}{ flaming_both } & \multirow{2}{*}{ Total } \\
\cline { 3 - 5 } & & 00 & 1.00 & To \\
\hline Gender & 1 & 39 & 12 & 51 \\
& 2 & 22 & 17 & 39 \\
Total & 61 & 29 & 90 \\
\hline
\end{tabular}




\section{Issues in Information Systems}

Volume 13, Issue 1, pp. 340-349, 2012

Table 6: Gender * identiy_cont Cross-tabulation

\begin{tabular}{|ll|l|l|l|l|}
\hline \multirow{5}{*}{} & \multicolumn{4}{l|}{ identity_cont } & \multirow{2}{*}{ Total } \\
\cline { 2 - 5 } & .00 & 1.00 & 2.00 & 52 \\
\hline Gender & 1 & 35 & 14 & 3 & 35 \\
& 2 & 17 & 10 & 8 & 87 \\
\hline
\end{tabular}

Table 7: Gender * stalking_cont Cross-tabulation

\begin{tabular}{|ll|l|l|l|l|}
\hline \multicolumn{5}{|c|}{} & \multicolumn{2}{l|}{ stalking_cont } & \\
\cline { 3 - 5 } & & 00 & 1.00 & 2.00 & Total \\
\hline Gender & 1 & 35 & 13 & 4 & 52 \\
& 2 & 15 & 10 & 9 & 34 \\
Total & & 50 & 23 & 13 & 86 \\
\hline
\end{tabular}

Table 8: Gender * flaming_cont Cross-tabulation

\begin{tabular}{|ll|l|l|l|l|}
\hline \multicolumn{5}{|c|}{} & \multicolumn{2}{l|}{ flaming_cont } & \multirow{2}{*}{ Total } \\
\cline { 2 - 5 } & & 00 & 1.00 & 2.00 & 51 \\
\hline Gender & 1 & 39 & 9 & 3 & 39 \\
& 2 & 22 & 11 & 6 & 90 \\
\hline
\end{tabular}

Table 9: Gender * privacy_cont Cross-tabulation

\begin{tabular}{|ll|l|l|l|l|}
\hline \multicolumn{5}{|c|}{} & \multicolumn{2}{l|}{ privacy_cont } & \multirow{2}{*}{ Total } \\
\cline { 2 - 5 } & & 00 & 1.00 & 2.00 & 44 \\
\hline Gender & 1 & 26 & 15 & 3 & 34 \\
& 2 & 10 & 14 & 10 & 78 \\
\hline
\end{tabular}

If we look at their reasons for joining and their reasons for continuing, all 8 reasons in question showed an increase from when they first joined Facebook. The highest reported reason was to make new friends and the lowest reported reason was that it was enjoyable and relaxing. While the all of the reasons showed an increase, and the increases were not the same across all reasons, the relative ranking of the 8 reasons did not change over time. 


\section{Issues in Information Systems}

Volume 13, Issue 1, pp. 340-349, 2012

Table 10: Reasons for joining and continuing the usage of Facebook

\begin{tabular}{|l|l|l|l|l|l|}
\hline & \multicolumn{7}{l}{ Joining } & \multicolumn{1}{l|}{ Continuing } \\
\hline REASONS & $\mathrm{N}$ & $\%$ & $\mathrm{~N}$ & $\%$ & Diff \\
\hline To be less inhibited & 15 & $12 \%$ & 19 & $15 \%$ & 4 \\
To share my problems & 9 & $7 \%$ & 17 & $13 \%$ & 8 \\
To make new friends & 30 & $24 \%$ & 38 & $30 \%$ & 8 \\
Escape from normal life & 16 & $13 \%$ & 26 & $21 \%$ & 10 \\
Enjoyable and relaxing & 34 & $27 \%$ & 45 & $36 \%$ & 11 \\
Let people know I care & 18 & $14 \%$ & 30 & $24 \%$ & 12 \\
Need someone to talk to & 15 & $12 \%$ & 27 & $21 \%$ & 12 \\
Help and encourage others & 20 & $16 \%$ & 37 & $29 \%$ & 17 \\
\hline
\end{tabular}

An ANOVA of the reasons, both for joining and for counting, based on gender produced significant differences in the "let People Know I Care" reason. There were significant differences only in the continuing group for the "Help and encourage others"

Table 11: ANOVA for the reasons for joining

\begin{tabular}{|ll|l|l|l|l|l|}
\hline ANOVA & \multicolumn{2}{|l|}{ Sum of Squares } & df & Mean Square & F & Sig. \\
\hline Care start & Between Groups & 4.594 & 1 & 4.594 & 6.916 & .010 \\
& Within Groups & 88.340 & 133 & .664 & & \\
& Total & 92.933 & 134 & & & \\
\hline care_cont & Between Groups & 7.131 & 1 & 7.131 & 9.282 & .003 \\
& Within Groups & 102.173 & 133 & .768 & & \\
& Total & 109.304 & 134 & & & \\
\hline help_cont & Between Groups & 4.011 & 1 & 4.011 & 4.676 & .032 \\
& Within Groups & 114.093 & 133 & .858 & & \\
& Total & 118.104 & 134 & & & \\
\hline
\end{tabular}




\section{Issues in Information Systems}

Volume 13, Issue 1, pp. 340-349, 2012

Counts for the groups are shown below:

Table 12: Gender * care_both Cross-tabulation

\begin{tabular}{|ll|l|l|l|l|}
\hline \multicolumn{5}{|c|}{} & \multicolumn{2}{l|}{ Care start } & \\
\cline { 2 - 5 } & & 00 & 1.00 & 2.00 & Total \\
\hline Gender & 1 & 56 & 10 & 15 & 81 \\
& 2 & 23 & 15 & 16 & 54 \\
Total & & 79 & 25 & 31 & 135 \\
\hline
\end{tabular}

Table 13: Gender * care_cont Cross-tabulation

\begin{tabular}{|ll|l|l|l|l|}
\hline \multicolumn{5}{|c|}{} & \multicolumn{2}{l|}{ care_cont } & \multirow{2}{*}{ Total } \\
\cline { 3 - 6 } & & 00 & 1.00 & 2.00 & 81 \\
\hline Gender & 1 & 56 & 7 & 18 & 54 \\
& 2 & 23 & 8 & 23 & 135 \\
\hline
\end{tabular}

Table 14: Gender * help_cont Cross-tabulation

\begin{tabular}{|ll|l|l|l|l|}
\hline \multicolumn{5}{|l|}{} & \multicolumn{2}{l|}{ help_cont } & \multirow{2}{*}{ Total } \\
\cline { 3 - 5 } & & 00 & 1.00 & 2.00 & 81 \\
Gender & 1 & 46 & 10 & 25 & 54 \\
& 2 & 22 & 5 & 27 & 135 \\
\hline
\end{tabular}

\section{DISCUSSIONS}

Our data suggests some interesting findings in the terms of our research question. For research question 1: What are some of the privacy concerns of undergraduate students upon joining a SNS such as Facebook? We found that students are generally not very concerned about their privacy situation on Facebook. A majority of students suggested that they were aware of the privacy threats to their personal information and knew that the data they post on Facebook can be viewed by future potential employers. Surprisingly, this knowledge did not deter these students from posting personal sensitive information on their Facebook site. This is an interesting insight considering the students claim to understand the privacy implications of their posts on Facebook but still continue to share information. Similar results have been noted in recent research studies regarding this dichotomy. Jung et al (2011) found that privacy concerns of users do not impact their usage of SNS. They argue that users mainly focus on the benefits which they will gain from continuing to use OSN, as the benefits are the purpose of their usage. Users might recognize that privacy risks are very small or they might not consider benefits and costs at the same time. It is also possible that the users may place little value on privacy in an SNS context (Acquisti, John, and Loewenstein, 2009). 


\section{Issues in Information Systems}

Volume 13, Issue 1, pp. 340-349, 2012

Our second research question: Is there a difference in perception due to the gender of the user about the privacy concerns on Facebook? We found that there is a significant difference between the female users and their attitude towards privacy of Facebook data compared to male users. Flaming, stalking and privacy were concerns that apparently make female users of Facebook more sensitive about the kind of information that they share. These concerns did not appear to be significant for the male population of Facebook users.

Finally our third research question: How do the privacy concerns of the users change with continued usage of Facebook over time? Our data suggests that the motivations for the students in joining Facebook have remained steady over time. The students have continued to use Facebook for similar reasons as they had initially started using it for. The results also suggested that there was a significant difference between male and females groups regarding one particular motivation for joining Facebook, namely the "Let people know I care" dimension. This is a unique result from the research. Also, there was a significant difference between the groups in the continuing group for the dimension "Help and encourage others". Thus it can be inferred that the feeling of helping and reaching out to friends is being strengthened by continued usage of Facebook.

\section{CONTRIBUTIONS AND LIMITATIONS}

This study contributes to the research literature in multiple ways. First, this study articulates that the motivations of the students in joining Facebook have remained steady after using it for a period of time. Their motivations for continuing to use it remain the same, which suggests that these young adults are broadly satisfied with their Facebook experience. This insight is unique in the sense there has not been much research in the reasons leading students to continue using SNS services. Second, this study suggests that the female population of Facebook users is more sensitive to privacy, flaming and stalking concerns on Facebook than the male population. This is a unique insight suggesting a significant difference in privacy concerns based on gender. Third, this study suggests that privacy concern is something that students do not take seriously. They understand that their information can be misused but have not grasped the idea that they need to change their information sharing behavior to reduce this risk. This insight could have implications for both the users and the service providers at these SNSs.

One of the biggest limitations of this study is that the sample base is centered at one particular university and also in a specific Intro level class. The data thus may not be the most representative sample for Facebook users overall. We can address this by offering this survey at multiple schools across various courses with more mature students. Also, data collected through the survey has limitations of any typical survey, such as self- reporting bias. Finally, the concept of privacy of personal data is a multidimensional concept and students could have very diverse interpretations of this construct in their mind. With complex constructs such as privacy of data, it is difficult to establish a common definitive initial understanding for all respondents. Hence, marked variation might occur in the responses due to the values attached to the privacy theme of the survey.

\section{CONCLUSION}

This paper explored the various reasons of students joining popular SNS such as Facebook, and their motivations to continue using these services. A survey was conducted for the freshmen class of Intro level courses at a northeastern city in the USA at a private college. Results were analyzed using SPSS. The results were discussed in the context of research literature in the relevant area, contributions were listed and limitations of the study were acknowledged.

Our findings suggest a difference in perception of privacy risks between males and females using Facebook. It also shows the knowledge of privacy threats alone might not be enough to deter young adults in college from sharing personal information on such sites. These findings have multiple implications for various stakeholders in the SNS context, such as users, administrators, advertisers and government. It would be a prime area of academic interest to pursue this line of inquiry in the immediate time frame. 


\section{Issues in Information Systems}

Volume 13, Issue 1, pp. 340-349, 2012

\section{REFERENCES}

1. Acquisti, A., John, L. and Loewenstein, G. (2009) What is Privacy Worth?, Technical Report, Heinz College, Carnegie Mellon University.

2. Acquisti, A. and Gross, R. (2006) in Golle, P. and Danezis, G. (Eds), "Imagined communities: awareness, information sharing, and privacy on the Facebook", Proceedings of $6^{\text {th }}$ Workshop on Privacy Enhancing Technologies, 28-30 June, Robinson College, Cambridge, UK.

3. Al Hasib, A. (2009), "Threats of online social networks", IJCSNS International Journal of Computer Science and Network Security, Vol. 9 No. 11, pp. 288-93.

4. Aricak, T., Siyahhan, S., Uzunhasanoglu, A., Saribeyoglu, S., Ciplak, S., Yismaz, N. and Memmedov, C. (2008), "Cyberbullying among Turkish adolescents", CyberPsychology \& Behavior, Vol. 11 No. 3, pp. 253-61.

5. Chen, R. (2011). Theoretical Framework for Understanding Interpersonal Privacy Protection on Social Network Sites, Proceedings of the Seventeenth Americas Conference on Information Systems, Detroit, Michigan August 4th-7th 2011

6. Dinev, T. and Hart, P. (2006) An Extended Privacy Calculus Model for E-Commerce Transactions, Information Systems Researc, $h$ 17, 1, 61-80

7. Fuchs, C. (2010), "studiVZ: social networking in the surveillance society", Ethics and Information Technology, Vol. 12 No. 2, pp. 171-85.

8. Gross, R., Acquisti, A. and Heinz Iii, H.J. (2005) in De Capitani Di Vimercati, S. and Dingledine, R. (Eds), "Information revelation and privacy in online social networks (The Facebook case)", Proceedings of the 2005 ACM Workshop on Privacy in the Electronic Society (WPES), 5-7 November, ACM, Alexandria, VA.

9. Hugl, U. (2011). Reviewing person's value of privacy of online social networking, Internet Research, Vol. 21 No. 4, 2011, pp. 384-407

10. Hogben, G. (2007). "Security issues and recommendations for online social networks." Position Paper. ENISA, EuropeanNetwork and Information Security Agency.

11. Jones, H. and J. Soltren (2005). "Facebook: Threats to privacy." Project MAC: MIT Project on Mathematics and Computing

12. Jung, E., McKnight, D., Jung, E. and Lankton, N. (2011) The Surprising Lack of Effect of Privacy Concerns on Intention to Use Online Social Networks, Proceedings of the Seventeenth Americas Conference on Information Systems, Detroit, Michigan August 4th-7th 2011

13. Rosenblum, D. (2007), "What anyone can know: the privacy risks of social networking sites", IEEE Security \& Privacy, Vol. 5 No. 3, pp. 40-9.

14. Strater, K. and Lipford, H.R. (2008), "Strategies and struggles with privacy in an online social networking community", Proceedings of the 22nd British HCI Group Annual Conference on People and Computers: Culture, Creativity, Interaction, 1-5 September, British Computer Society, Liverpool.

15. Valkenburg, P.M. and Peter, J. (2009), "Social consequences of the internet for adolescents: a decade of research", Current Directions in Psychological Science, Vol. 18 No. 1, pp. 1-5.

16. Xu, H. (2007). The effects of self-construal and perceived control on privacy concerns. Proceedings of 28th Annual International Conference on Information Systems (ICIS), Montréal, Canada

17. Hempel, J. and P. Lehman (2005). "The MySpace Generation." Business Week 3963: 86

18. Felt, A. and D. Evans (2008). "Privacy protection for social networking APIs." 2008 Web 2.0 Security and Privacy (W2SP'08).

19. Krasnova, H., S. Spiekermann, et al. (2010). "Online social networks: why we disclose." Journal of Information Technology 25(2): 109-125.

20. Boyd, D. (2008). "Facebook's privacy trainwreck: Exposure, invasion, and social convergence." Convergence: The International Journal of Research into New Media Technologies 14(1): 13-20. 